JOURNAL OF MANAGEMENT OF AQUATIC RESOURCES.

Volume 1, Nomor 1, Tahun 2012, Halaman 1- 6

Online di : http://ejournal-s1.undip.ac.id/index.php/maquares

\title{
KELIMPAHAN HEWAN MAKROBENTOS YANG BERASOSIASI PADA HABITAT LAMUN DENGAN JARAK BERBEDA DI PERAIRAN PULAU PRAMUKA KEPULAUAN SERIBU
}

\author{
Nurul Ekaningrum, Ruswahyuni dan Suryanti *)
}

Jurusan Perikanan, Fakultas Perikanan dan Ilmu Kelautan, Universitas Diponegoro Jl. Prof. H. Soedharto, SH, Tembalang Semarang. 50275 Telp/Fax (024) 7474698

\begin{abstract}
Abstrak
Penelitian ini dilaksanakan pada bulan April 2012 di Pulau Pramuka, Kepulauan Seribu. Teknik pengambilan sampel menggunakan metode sistematik sampling artinya sampling yang disusun dengan lokasi dan waktu sampling dibuat dengan pola teratur. Hasil penelitian menunjukkan bahwa jenis lamun yang ditemukan di Pulau Pramuka Kepulauan Seribu adalah Enhalus acoroides, Thalassia hemprichii, Cymodocea rotundata, Halophila ovalis dan Syringodium. Kelimpahan hewan makrobentos pada habitat lamun dengan jarak berbeda, yaitu Stasiun A (6 meter) 10 spesies dengan 52 individu dan Stasiun B (50 meter) 12 spesies dengan 69 individu. Nilai Indeks Keanekaragaman $\left(H^{\prime}\right)$ hewan makrobentos pada Stasiun A dan Stasiun B sebesar 2,29 dan 2,39. Nilai Indeks Keseragaman (E) pada Stasiun A dan Stasiun B sebesar 0,95 dan 0,96. Dari hasil uji T- Test didapatkan nilai signifikan sebesar 0,159 $(P<0,005)$, yang berarti tidak ada perbedaan yang signifikan kelimpahan hewan makrobentos pada habitat lamun dengan jarak berbeda atau relatif seragam.
\end{abstract}

Kata kunci : Lamun, Kelimpahan Hewan Makrobentos, Pulau Pramuka

\begin{abstract}
This reseacrh has been conducted on April 2012 in the Pramuka Island, Kepulauan Seribu. Systematic sampling method was used to sampling of makrozoobenthos with the location and time of sampling was made in a regular pattern. The results showed that the type of the seagrass found in Pramuka Island Kepulauan Seribu are Enhalus acoroides, Thalassia hemprichii, Cymodocea rotundata, Halophila ovalis and Syringodium. The abundance of makrozoobenthos on habitat of seagrass with different distances are Station A (6 meters) 10 species with 52 individuals and Station B (50 meters) 12 species with 69 individuals. Value Diversity Index ( $H$ ') makrozoobenthos at Station A and Station B are about 2,29 and 2,39. Value Evenness Index $(E)$ in Stasiun A and Stasiun B are about 0,95 dan 0,96. The test $T$-Test results obtained significant value of $0.159(P<0.005)$, which means there is no significant difference on abundance of makrozoobenthos in habitat of seagrass with different distance or relatively uniform.
\end{abstract}

Keywords: Seagrass, Abudance Makrozoobenthos, Pramuka Island

\section{Pendahuluan}

Lamun berfungsi sebagai tempat tinggal, tempat memijah atau bertelur, mencari makan dan berlindung/shelter sekaligus daerah asuhan dari banyak jenis ikan, krustacea, molluska dan echinodermata. Berdasarkan temuan pihak BTNKpS dari 12 jenis lamun yang tumbuh di Perairan Indonesia, 7 jenis diantaranya dapat ditemukan di kawasan Taman Nasional Kepulauan Seribu (BTNKpS, 2005). Perubahan yang terjadi pada padang lamun dapat mempengaruhi keberadaan biota yang berasosiasi dengannya. Rusaknya padang lamun yang disebabkan oleh limbah, aktivitas manusia, pengerukan pasir dan sebagainya berarti merusak habitat bagi sejumlah besar biota yang hidup di padang lamun. Hewan makrobentos adalah kelompok yang berasosiasi dengan lamun. Dimana kelompok hewan makrobentos ini terdiri dari jenis Polychaeta, Mollusca (Gastropoda) dan Enchinodermata. Hewan makrobentos mempunyai peranan yang sangat penting dalam siklus nutrien di dasar perairan. Montagna et al. (1989) dalam Suartini et al. (2006), menyatakan bahwa dalam ekosistem perairan, hewan makrobentos berperan sebagai salah satu mata rantai penghubung dalam aliran energi dan siklus dari alga planktonik sampai konsumen tingkat tinggi. Kikuchi dan Peres (1997) dalam

\footnotetext{
${ }^{*}$ Penulis Penanggung Jawab
} 
Ongkers (1990), menjelaskan bahwa organisme yang berasosiasi pada ekosistem lamun yaitu biota yang menempel pada batang dan rimpang (contohnya jenis Polychaeta yang sesil dan jenis Amphipoda), biota yang hidup dibawah tajuk daun (berupa ikan, udang, kepiting dan cumi-cumi) serta biota epifauna (Polychaeta dan Bivalve). Penelitian ini bertujuan untuk mengetahui jenis lamun, mengetahui kelimpahan hewan makrobentos serta mengetahui apakah ada perbedaan kelimpahan hewan makrobentos pada habitat lamun dengan jarak berbeda di Perairan Pramuka Kepulauan Seribu, Jakarta. Penelitian ini telah dilakukan tanggal 9-22 April di Perairan Pantai Pulau Pramuka, Kepulauan Seribu

\section{Materi dan Metode Penelitian}

A. Materi Penelitian

Materi yang digunakan dalam penelitian ini meliputi data lapangan (data primer) dan data pendukung (data sekunder). Data primer meliputi yaitu kerapatan lamun dan kelimpahan hewan makrobentos di Perairan Pulau Pramuka, Kepulauan Seribu. Sedangkan data sekunder meliputi pengukuran suhu, salinitas, kecerahan, kecepatan arus, kedalaman dan $\mathrm{pH}$.

\section{B. Metode Penelitian, Pengolahan dan Analisi Data}

\section{Metode Penentuan Lokasi Sampling}

Metode yang digunakan adalah metode survey yang bersifat deskriptif (Notoatmodjo, 2002). Pengambilan sampel menggunakan metode sistematik sampling, yaitu sampling yang disusun dengan lokasi dan waktu sampling dibuat dengan pola teratur (Dharma dan Ketut, 2009). Pemilihan lokasi sampling yang pertama berdasarkan dari lamun yang berada pada jarak 6 meter (Stasiun A) dimana lamun pada lokasi ini tidak mengalami paparan ombak yang tinggi sedangkan lokasi sampling kedua berdasarkan dari lamun yang berada pada jarak 50 meter (Stasiun B) dimana pada lokasi ini terkena paparan ombak.

\section{Pengambilan Sampel Hewan Makrobentos}

Pengambilan sampel hewan makrobentos dilakukan pada Perairan Pulau Pramuka dengan mengambil 2 stasiun, dimana Stasiun A yaitu lamun dengan jarak 6 meter dan Stasiun B yaitu pada lamun dengan jarak 50 meter. Setiap stasiun ditentukan 5 titik sampling dan pada setiap sampling dilakukan 3 kali ulangan. Buku Identifikasi hewan makrobentos yang digunakan dalam penelitian yaitu Day (1967) ${ }^{\mathrm{a}}$, Day (1967) $)^{\mathrm{b}}$ dan Roberts et al. (1982).

\section{Analisis Data}

Setelah data-data didapat, kemudian dilakukan pengolahan data yang terdiri dari kelimpahan, kelimpahan relatif, Indeks Keanekaragaman (H') dan Indeks Keseragaman (E) dan uji T-Test.

\section{Hasil dan Pembahasan}

\section{Jenis dan Kerapatan Lamun}

Kerapatan lamun yang didapatkan pada stasiun pengamatan di Pulau Pramuka, Kepulauan Seribu tersaji dalam Tabel 1.

Tabel 1. Kerapatan Lamun (individu/ $\mathrm{m}^{2}$ ) di Pulau Pramuka Kepulauan Seribu

\begin{tabular}{|c|c|c|c|}
\hline \multirow[b]{2}{*}{ No. } & \multirow[b]{2}{*}{ Spesies Lamun } & \multicolumn{2}{|c|}{ Stasiun } \\
\hline & & $\mathbf{A}$ & B \\
\hline 1. & Enhalus acoroides & 22 & 34 \\
\hline 2. & Thalassia hemprichii & 448 & 386 \\
\hline 3. & Cymodocea rotundata & 239 & 88 \\
\hline 4. & Halophila ovalis & 0 & 52 \\
\hline 5. & Syringodium & 0 & 61 \\
\hline & $\begin{array}{l}\text { Jumlah Spesies (s) } \\
\text { Jumlah Individu } \\
\text { H' }\end{array}$ & $\begin{array}{c}3 \\
709 \\
0,77\end{array}$ & $\begin{array}{c}5 \\
621 \\
1,17\end{array}$ \\
\hline
\end{tabular}

Berdasarkan pengamatan lamun yang dilakukan pada dua stasiun pengamatan di Pulau Pramuka di temukan lima spesies lamun yaitu Enhalus acoroides, Halophila ovalis, Thalassia hemprichii, Cymodocea rotundata dan Syringodium. Pada ke dua stasiun pengamatan yaitu Stasiun A (6 meter) dan Stasiun B (50 meter) didapatkan jumlah individu lamun yang banyak pada Stasiun A sebanyak 709 individu $/ \mathrm{m}^{2}$ dan jumlah individu yang sedikit terdapat di stasiun B sebanyak 621 individu $/ \mathrm{m}^{2}$.

Pada Stasiun A ditemukan tiga jenis lamun, yaitu Enhalus acoroides, Thalassia hemprichii dan Cymodocea rotundata dengan komposisi terbesar adalah jenis Thalassia hemprichii mencapai 63\% dibandingkan dengan Enhalus acoroides yang hanya 3\%. Jenis lamun Syringodium dan Halophila ovalis tidak ditemukan di Stasiun A, hal ini diduga karena kedalaman perairan yang tergolong dangkal. Menurut Kuriandewa (2009), lamun jenis ini tidak dijumpai di daerah yang mengalami pemaparan saat surut.

Pada kedua stasiun jenis lamun yang mendominasi adalah Thalassia hemprichii. Lamun dugong (Thalassia Hemprichii) mampu tumbuh dan berkembang dalam kondisi tak beroksigen (anoxia) atau berkadar oksigen rendah yang 
merupakan sifat habitat pasang surut yang dangkal sehingga mampu berkoloni di habitat laut dangkal dengan berhasil dan mengusir sebagian kelompok tumbuh-tumbuhan lainnya (Romimohtarto dan Juwana, 2007).

Pada Stasiun A yang jarak 6 meter dimana kondisi arus yang tenang menyebabkan kandungan nutrien menjadi minim, hal ini yang menjadi kunci untuk bertahannya lamun dari hempasan gelombang. Menurut Wicks et all (2009) dalam Priosambodo (2011), lamun yang hidup di alam dengan kondisi nutrien yang minim, memiliki sistem perakaran yang panjang dan rumit didalam substrat, karena harus mencari zat hara yang cukup untuk tumbuh. Oleh karena itu sistem perakaran lamun pada Stasiun A yang kuat akan menjamin tegakan lamun untuk bertahan dari hempasan ombak

Nilai Indeks Keanekaragaman lamun yang rendah pada Stasiun A disebabkan karena hanya ditemukan 3 spesies yaitu Enhalus acoroides, Thalassia hemprichii dan Cymodocea rotundata. Hal ini sesuai dengan pernyataan dari Soegianto (1994), jika suatu komunitas disusun oleh sangat sedikit jenis dan hanya sedikit jenis yang dominan maka keanekaragaman jenisnya rendah.

\section{Jenis dan Kelimpahan Hewan Makrobentos}

Hewan makrobentos yang didapat pada stasiun pengamatan di Pulau Pramuka, Kepulauan Seribu tersaji dalam Tabel 2.

Tabel 2. Kelimpahan Hewan Makrobentos (individu/ $\mathrm{m}^{3}$ ) di Pulau Pramuka Kepulauan Seribu

\begin{tabular}{|c|c|c|c|}
\hline \multirow{2}{*}{ No. } & \multirow{2}{*}{ Biota } & \multicolumn{2}{|c|}{ Stasiun } \\
\hline & & $\mathbf{A}$ & B \\
\hline & Polychaeta & & \\
\hline 1. & Neries sp & 11 & 14 \\
\hline 2. & Capitela sp & 5 & 7 \\
\hline 3. & Polydora sp & 5 & 6 \\
\hline 4. & Heteromastus sp & 4 & 6 \\
\hline 5. & Sigambra sp & 7 & 6 \\
\hline 6. & Prionospio $s p$ & 8 & 5 \\
\hline 7. & $\begin{array}{l}\text { Scolelepis sp } \\
\text { Bivalve }\end{array}$ & 0 & 4 \\
\hline 8. & Tellina sp & 4 & 6 \\
\hline 9. & Macoma $s p$ & 2 & 3 \\
\hline 10. & $\begin{array}{l}\text { Donax } s p \\
\text { Gastropoda }\end{array}$ & 3 & 3 \\
\hline 11. & Strombus $s p$ & 3 & 5 \\
\hline 12. & Nerita $s p$ & 0 & 4 \\
\hline & $\begin{array}{l}\text { lah Spesies (s) } \\
\text { lah Individu }\end{array}$ & $\begin{array}{l}10 \\
52\end{array}$ & $\begin{array}{l}12 \\
69\end{array}$ \\
\hline
\end{tabular}

Berdasarkan pengamatan terhadap hewan makrobentos pada dua stasiun di Pulau Pramuka di temukan Polychaeta, Bivalve dan Gastropoda. Dimana untuk Polycaeta ditemukan 7 spesies yaitu Neries sp, Capitela sp, Polydora sp, Heteromastus sp, Sigambra sp, Prionospio sp dan Scolelepis sp. Bivalve ditemukan 3 spesies yaitu Tellina sp, Macoma sp dan Donax sp. Gastropoda ditemukan 2 spesies yaitu Strombus sp dan Nerita sp.

Dari kedua stasiun di Pulau Pramuka, Stasiun B ditemukan paling banyak hewan makrobentos dibandingkan dengan Stasiun A. Stasiun A hanya ditemukan 10 biota yang terdiri dari Polychaeta sebanyak 6 spesies (Neries sp, Capitela sp, Polydora sp, Heteromastus sp, Sigambra sp, dan Prionospio sp), Bivalve sebanyak 3 spesies (Tellina sp, Macoma sp dan Donax sp) dan Gastropoda sebanyak 1 spesies yaitu Strombus sp sedangkan pada Stasiun B ditemukan 12 biota yang terdiri dari Polychaeta sebanyak 7 spesies (Neries sp, Capitela sp, Polydora sp, Heteromastus sp, Sigambra sp, Prionospio sp dan Scolelepis sp), Bivalve sebanyak 3 spesies (Tellina sp, Macoma sp dan Donax sp) dan Gastropoda sebanyak 2 spesies (Strombus sp dan Nerita sp).

Pada ketiga kelas yang meliputi Polychaeta (7 spesies), Bivalvia (3 spesies) dan Gastropoda (2 spesies) (tabel 2) terlihat kelas Polychaeta memiliki frekuensi kemunculan tertinggi karena hewan ini selalu ditemukan pada stasiun penelitian yaitu Stasiun A (6 meter) dan Stasiun B (50 meter). Komposisi kelas Polychaeta yang didapat di stasiun penelitian lebih besar daripada komposisi kelas lainnya dan kondisi ini seperti pendapat Sanders (1968), yang menyatakan bahwa pada umumnya komposisi hewan makrobentos di segala area terdiri dari kelompok Polichaeta 50 60\%, sedangkan sisanya adalah Mollusca, Crustacea dan Enchinodermata.

Pada Tabel 2 terlihat bahwa Nereis sp paling mendominasi dibandingkan dengan spesies lain sedangkan untuk Bivalve, spesies yang paling umum ditemukan adalah Macoma sp dimana kondisi ini sesusai dengan pendapat Sumich (1992), yang menyatakan organisme hewan makrobentos yang umum di jumpai pada pantai berpasir adalah: Bivalve (Macoma sp), beberapa Polychaeta seperti Nereis sp dan beberapa dari famili Capitellidea. 
Kelimpahan hewan makrobentos pada Stasiun B lebih tinggi dibandingkan pada Stasiun A, hal ini disebabkan pada Stasiun B yang terkena paparan ombak memiliki kandungan nutrien dan oksigen yang baik karena terjadi pembaharuan bahan organik. Kondisi ini sesuai dengan pendapat Larkum et al. (2006) yang menyatakan bahwa perpindahan air yang lebih cepat/kuat dapat meningkatkan suplai makanan untuk organisme pemakan suspensi. Unsur berbahaya hasil dekomposisi, seperti sulfur dan nitrit yang terlepas dari dalam sedimen dapat dinetralisir. Selain itu kelimpahan tertinggi pada Stasiun B dikarenakan hewan makrobentos, sebagai contoh spesies Donax sp pada saat ombak datang akan melindungi diri dengan cara bersembunyi/meliang masuk ke dalam substrat.

Arus memiliki pengaruh positif dan negatif terhadap kehidupan biota perairan. Dimana arus dapat memperbaharui bahan-bahan organik yang bermanfaat bagi makrobentos untuk makanan tetapi arus juga dapat mengakibatkan kekeruhan air sehingga penetrasi cahaya matahari berkurang. Kecepatan arus pada stasiun B lebih kuat daripada Stasiun A. Kecepatan arus pada Stasiun A yaitu $0,001 \mathrm{~m} / \mathrm{s}$, hal ini menyebabkan kurangnya pembaharuan bahan organik dan kandungan oksigen yang rendah sehingga mempengaruhi kelimpahan hewan makrobentos. Menurut Wood (1987), pada daerah dengan kecepatan arus sedang yaitu $10-100 \mathrm{~cm} / \mathrm{s}$ menguntungkan bagi organisme dasar karena terjadi pembaharuan antara bahan organik dan anorganik dan tidak terjadi akumulasi

\section{Indeks Keanekaragaman (H') dan Keseragaman (E)}

Tabel 3. Indeks Keanekaragaman (H’) dan Keseragaman (E) Hewan Makrobentos di Pulau Pramuka

\begin{tabular}{ccc}
\hline Stasiun & Indeks Keanekaragaman $\left(\mathrm{H}^{\prime}\right)$ & Keseragaman $(\mathrm{E})$ \\
\hline $\mathrm{A}$ & 2,29 & 0,95 \\
$\mathrm{~B}$ & 2,39 & 0,96 \\
\hline
\end{tabular}

Berdasarkan hasil tabel 3, diketahui bahwa keanekaragaman jenis hewan makrobentos dari masing-masing stasiun di Pulau Pramuka memiliki nilai yang berbeda-beda, dengan kecenderungan nilai yang sedikit lebih tinggi pada Stasiun B. Keanekaragaman jenis hewan makrobentos pada Stasiun B memiliki indeks keanekaragaman 2,39 sedangkan pada Stasiun A nilai indeks keanekaragaman yaitu 2,29. Dimana Hal ini menandakan bahwa indeks keanekaragaman termasuk dalam kategori tinggi yang artinya penyebaran jumlah individu tiap spesies dan kestabilan komunitas tinggi. Meskipun termasuk dalam kategori tinggi, kedua stasiun ini memiliki perbedaan jumlah spesies yaitu pada Stasiun B untuk Polychaeta terdapat 7 spesies dan Gastropoda terdapat 2 spesies sedangkan pada Stasiun A untuk Polychaeta hanya terdapat 6 spesies dan Gastropoda terdapat 1 spesies. Hal ini yang membuat nilai indeks keanekaragaman di Stasiun B cenderung tinggi dibandingkan Stasiun A.

Nilai indeks keseragaman pada Stasiun A adalah 0,95 sedangkan Stasiun B adalah 0,96. Berdasarkan data tersebut, nilai indeks keanekaragaman tiap stasiun > 0,6 yang berarti keseragaman kelimpahan tinggi. Menurut Brower et al. (1990) termasuk dalam kategori keseragaman kelimpahan tinggi. Kategori tersebut memperlihatkan bahwa tidak terdapat dominasi oleh spesies tertentu dan kelimpahan jenis dapat dikatakan sama.

Hasil uji statistik perbandingan contoh dengan Uji T-Test pada taraf nyata 0,05 di stasiun pengamatan yang terletak di Pulau Pramuka menghasilkan nilai sig 0,159 dimana nilai sig > 0,05, berarti tidak ada perbedaan yang signifikan kelimpahan hewan makrobentos pada habitat lamun di Stasiun A dan stasiun B atau relatif seragam.

\section{Parameter Fisika dan Kimia Perairan}

Hasil pengukuran parameter fisika kimia perairan di Pulau Pramuka dapat dilihat pada Tabel 4.

Tabel 4. Hasil Parameter Fisika dan Kimia di Pulau Pramuka Kepulauan Seribu

\begin{tabular}{|c|c|c|c|c|}
\hline \multirow{2}{*}{ No. } & \multirow{2}{*}{ Parameter } & \multicolumn{2}{|c|}{ Stasiun } & \multirow{2}{*}{ Pustaka } \\
\hline & & $\bar{A}$ & $\mathrm{~B}$ & \\
\hline 1. & $\begin{array}{l}\text { A. Fisika } \\
\text { Suhu }\left({ }^{0} \mathrm{C}\right)\end{array}$ & 31 & 31 & $25-31^{\text {a) }}$ \\
\hline 2. & Kecerahan $(\mathrm{cm})$ & $\sim$ & $\sim$ & - \\
\hline 3. & Kedalaman $(\mathrm{cm})$ & 10 & 40 & - \\
\hline 4. & $\begin{array}{l}\text { Kecepatan arus }(\mathrm{m} / \mathrm{s}) \\
\text { B. Kimia }\end{array}$ & 0,001 & 0,083 & - \\
\hline 1. & $\mathrm{pH}$ & 7 & 7 & $<5$ dan $>9^{\text {b) }}$ \\
\hline 2. & Salinitas (\%o) & 31 & 31 & $15-35^{\mathrm{c})}$ \\
\hline
\end{tabular}

Sumber :

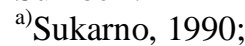

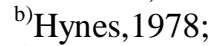

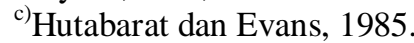


Berdasarkan hasil pengukuran, suhu berkisar antara $30-31^{0} \mathrm{C}$. Kisaran suhu masih berada dalam kisaran suhu optimum bagi hewan makrobentos dan pertumbuhan lamun. Menurut Dahuri (2003), kisaran suhu optimal bagi spesies lamun adalah $28-30^{\circ} \mathrm{C}$. Menurut Sukarno (1981), bahwa suhu dapat membatasi sebaran hewan makrobentos secara geografik dan suhu yang baik untuk pertumbuhan hewan makrobentos berkisar antara $25-31^{\circ} \mathrm{C}$.

Kecepatan arus pada Perairan Pulau Pramuka berkisar antar 0,001 hingga 0,083 m/s. Dimana kecepatan arus dikategorikan sedang dan menunjukkan dasar lumpur atau tanah organik. Menurut Wood (1987), pada daerah dengan kecepatan arus sedang yaitu $10-100 \mathrm{~cm} / \mathrm{s}$ menguntungkan bagi organisme dasar karena terjadi pembaharuan antara bahan organik dan anorganik dan tidak terjadi akumulasi.

Nilai $\mathrm{pH}$ pada lokasi penelitian adalah 7 . Nilai $\mathrm{pH}<5$ dan $>9$ menciptakan kondisi yang tidak menguntungkan bagi kebanyakan organisme makrobenthos (Hynes, 1978) sedangkan nilai pH optimum untuk pertumbuhan lamun berkisar 7,3 - 9,0 (Phillips, 1998 dalam Zulkifli dan Efriyeldi, 2003).

Salinitas pada lokasi penelitian adalah 31\%o. Menurut Hutabarat dan Evans (1985), kisaran salinitas yang masih mampu mendukung kehidupan organisme, khususnya fauna makrobenthos adalah 15-35\%. Hal ini menunjukkan bahwa kisaran salinitas yang ada dilokasi penelitian masih dalam kisaran nilai optimum.

\section{Substrat Dasar Perairan}

Hasil analisa substrat pada lokasi penelitian dapat dilihat pada Tabel 5.

Tabel 5. Hasil Analisis Tekstur Substrat Dasar (\%) di Pulau Pramuka

\begin{tabular}{lc}
\hline \multicolumn{1}{c}{ Tipe } & Persentase \\
\hline Gravel (Batu Kerikil) & $38,43 \%$ \\
Sand (Pasir) & $51,16 \%$ \\
Silt (Lanau/Endapan Lumpur) & $10,41 \%$ \\
Clay (Lempung) & $0,00 \%$ \\
\hline
\end{tabular}

Hasil analisa tekstur sedimen diperoleh pada lokasi penelitian terdiri dari 38,43\% Gravel, 51,16\% Pasir dan 10,41 Silt. Pada lokasi kandungan substrat dasar perairan didominasi oleh pasir namun kandungan Silt juga cukup tinggi sehingga mempengaruhi hewan makrobentos. Silt merupakan endapan lumpur yang diperoleh dari hasil pembuangan limbah dari penduduk stempat. Menurut Nybakken (1988), hewan makrobentos yang mempunyai sifat penggali dan pemakan deposit cenderung melimpah pada sedimen lumpur dan sedimen lunak yang mengandung bahan organik yang tinggi. Kelompok hewan makrobentos yang dominan ditemukan di perairan bersubstrat lumpur adalah Polychaeta dan Bivalvia, disamping itu juga ditemukan gastropoda dengan indeks keanekaragaman yang rendah.

\section{Kesimpulan}

Kesimpulan yang diperoleh dari penelitian ini adalah sebagai berikut:

1. Jenis lamun yang ditemukan di Pulau Pramuka Kepulauan Seribu adalah Enhalus acoroides, Thalassia hemprichii, Cymodocea rotundata, Halophila ovalis dan Syringodium. Kelimpahan hewan makrobentos pada lamun dengan jarak berbeda, yaitu Stasiun A (6 meter) 10 spesies dengan 52 individu dan Stasiun B (50 meter) 12 spesies dengan 69 individu.

2. Nilai sig pada stasiun pengamatan di Pulau Pramuka adalah 0,159 dimana nilai sig $>0,05$, berarti tidak ada perbedan kelimpahan hewan makrobentos pada habitat lamun dengan jarak berbeda atau relatif seragam.

\section{Daftar Pustaka}

Balai Taman Nasional Kepulauan Seribu. 2005. Penanaman Lamun di Kepulauan Seribu. Departemen Kehutanan Jakarta.

Brower, J.E., Zar, J.H and Ende von C.N. 1990. Field and Laboratory Methods for General Ecology Dubuque. WCB Publishers.

Dahuri, R. 2003. Keanekaragaman Hayati Laut, Aset Pembangunan Berkelanjutan Indonesia. PT Gramedia Pustaka Utama, Jakarta

Day, J.H. 1967 ${ }^{\mathrm{a}}$. A Monograph on the Polychaeta of Southern Africa, Pt I. Errantia. British Musium (Natural History), London.

$1967^{\mathrm{b}}$. A Monograph on the Polychaeta of Southern Africa, Pt 2. Sedentaria. British Musium (Natural History), London.

Dharma, P dan K. Gede. 2009. Petunjuk Teknis Pemantauan Kualitas Air. Udayana University Press, Denpasar.

Hynes, H. B. N. 1978. The Ecology of Running Waters. University of Toroto press. Toronto, 555p.

Hutabarat, S., and S. M. Evans. 1985. Pengantar Oseanografi. Universitas Indonesia Press, Jakarta.

Kuriandewa, T.E. 2009. Tinjauan tentang Lamun di Indonesia. Lokakarya Nasional I Pengelolaan Ekosistem Lamun, Jakarta. 
Larkum, A.W.D., Orth, R.J., and Duarte, C.M. (eds.). 2006. Seagrasses: Biology, Ecology and Conservation. Springer , The Netherland.

Notoatmodjo, S. 2002. Metodologi Penelitian Kesehatan. Rineka Cipta. Jakarta.

Nybakken, J. W. 1988. Biologi Laut. Suatu Pendekatan Ekologis. Diterjemahkan dari Marine Biology an Ecological Approach oleh M. Eidman . PT Gramedia Pustaka Utama, Jakarta.

Ongkers , O.T.S. 1990. Studi Kelimpahan Ikan Padang Lamun Tiram Teluk Ambon Bagian Dalam. Fakultas Pascasarjana, Institut Pertanian Bogor, Bogor.

Priosambodo, D. 2011. Struktur Komunitas Makrozoobentos di Daerah Padang Lamun Pulau Bone Batang Sulawesi Selatan. [Tesis]. Sekolah Pascasarjana, Institut Pertanian Bogor, Bogor.

Roberts, D., Soemodihardjo, S., and Kasworo, W. 1982. Shallow water Marine Molluscs North - West Java. LON LIPI, Jakarta.

Romimohtarto, K dan S. Juwana. 2007. Biologi Laut Ilmu Pengetahuan tentang Biota Laut. Djambatan, Jakarta.

Sanders. 1968. Marine benthic Diversity : A Comparative Study. Am. Nat. 102: 243-282 hlm.

Soegianto, A. 1994. Ekologi Kuantitatif Metode Analisis Populasi dan Komunitas. Usaha Nasional, Surabaya.

Suartini, Ni Made., Ni Wayan, Sudatri., Made Pharmawati., dan A. A. G, Raka Dalem. 2006. Identifikasi Makrozoobenthos di Tukad Bausan, Desa Pererenan, Kabupaten Badung, Bali. Jurnal Ecotrophic Universitas Udayana, Denpasar. Vol 5 (1): 41-44 hlm.

Sukarno, 1981. Terumbu Karang di Indonesia. Permasalahan dan Pengelolaannya. LON-LIPI, Jakarta.

Sumich, J.L. 1992. An Introduction To The Biology Of Marine Life. Ed ke-5. Dubuque:WMC Brown, 255-269 hlm.

Wood, M. S. 1987. Subtidal ecology. Edward Arnold Pty. Limited, Australia.

Zulkifli dan Efriyeldi. 2003. Kandungan Zat Hara dalam Air Poros dan Air Permukaan Padang Lamun Bintan Timur Riau. Jurnal Natur Indonesia. Vol 5(2): 139-144 hlm. 